\title{
Comparison of radiation parametrizations within the HARMONIE-AROME NWP model
}

\author{
Laura Rontu and Anders V. Lindfors \\ Finnish Meteorological Institute, Helsinki, Finland \\ Correspondence: Laura Rontu (laura.rontu@ fmi.fi)
}

Received: 6 February 2018 - Revised: 24 April 2018 - Accepted: 26 April 2018 - Published: 22 May 2018

\begin{abstract}
Downwelling shortwave radiation at the surface (SWDS, global solar radiation flux), given by three different parametrization schemes, was compared to observations in the HARMONIE-AROME numerical weather prediction (NWP) model experiments over Finland in spring 2017. Simulated fluxes agreed well with each other and with the observations in the clear-sky cases. In the cloudy-sky conditions, all schemes tended to underestimate SWDS at the daily level, as compared to the measurements. Large local and temporal differences between the model results and observations were seen, related to the variations and uncertainty of the predicted cloud properties.

The results suggest a possibility to benefit from the use of different radiative transfer parametrizations in a NWP model to obtain perturbations for the fine-resolution ensemble prediction systems. In addition, we recommend usage of the global radiation observations for the standard validation of the NWP models.
\end{abstract}

\section{Introduction}

Future numerical weather prediction (NWP) models will increasingly be devoted to very high-resolution and rapid updates due to the needs of forecasting details in short timescales. In order to account for the details of the cloud-aerosol-radiation and surface-radiation interactions in the high-resolution forecasting systems, fast but physically based radiative transfer parametrizations are necessary. In view of predictability challenges at high resolution it is desirable to apply probabilistic methods even at the short forecast ranges. Application of various radiation schemes may provide the ensemble prediction systems with realistic physics perturbations.

In response to the ongoing rapid development of the solar energy sector, the capability of NWP models to predict observed solar shortwave (SW) radiation conditions at the surface has been put under scrutiny in recent studies (LaraFanego et al., 2012; Kosmopoulos et al., 2015; Federico et al., 2017). Taking a step further, NWP models are also being applied for predicting the "energy weather". In case of solar energy, this means forecasting the potential solar photovoltaic energy production that corresponds to the weather conditions predicted by the NWP (e.g. Antonanzas et al.,
2016; Köhler et al., 2017). For the development of the solar energetics, observational data of downwelling shortwave radiation at the surface (SWDS) distribution are increasingly needed and measurement stations are being set up globally.

Observed radiation fluxes offer a possibility to validate NWP model results not only for the energy meteorology but also for general purposes (Rontu et al., 2017), or with respect to particular contributing factors such as clouds (Ahlgrimm and Forbes, 2012). Both solar and terrestrial radiation fluxes are related to the humidity and cloud physical properties, and terrestrial also to the air temperature. Observed and predicted downwelling radiation fluxes represent approximately the same spatial and temporal scales and are thus directly comparable. This is less true for e.g. the observed and predicted cloud cover or screen-level temperature that are routinely used for verification of the weather forecasts. However, rapid variations in the solar radiation fluxes on timescales of minutes, mostly related to the small-scale cloud variability, remain unresolved by the kilometre-scale NWP models. For model-observation comparisons, hourly and daily averaged observations are thus expected to be the most suitable.

Validation of radiation output from a 3-D NWP model against the radiation observations is useful for understand- 
ing the behaviour of the radiation parametrizations and their influence on the NWP results in interaction with all other simulated physical processes. Intercomparison of various parametrization schemes within a single NWP model - instead of the comparison of different NWP models containing specific radiation schemes - enables an equal framework also for their validation against the observations.

In this study, we report intercomparison of three alternative radiation schemes that have been made available within the HARMONIE-AROME NWP model (based on version $40 \mathrm{~h} 1)^{1}$ and compare the results to the global radiation measurements over Finland during spring 2017. The aim of the study is to reveal and understand the differences of the model results due to the different radiation parametrizations, applying the full 3-D HARMONIE-AROME experiments.

Preliminary studies of this kind were reported by Kangas et al. (2016), Rontu et al. (2016, 2017) and Nielsen et al. (2017). They found local and temporal differences of the NWP results due to the different radiation parametrizations and suggested that these were mainly related to the cloud variations and the uncertainties of cloud forecast. Here we search for confirmation of the preliminary findings before suggesting introduction of the three radiation schemes into operational usage within HARMONIE-AROME. In particular, we would like to understand the possible systematic differences in the model results due to application of radiation parametrizations of different levels of complexity. Can we rely on every scheme in spite of the possible differences? We expect to see local and temporal variations due to the different parametrizations, especially with respect to cloudradiation interactions. Is it possible to benefit from these differences when developing an ensemble forecasting system?

This article is outlined as follows: Sect. 2 documents the IFSRADIA, ACRANEB and HLRADIA radiative transfer schemes applied. Section 3 presents the spring 2017 comparisons: observations and HARMONIE-AROME experiments as well as the diagnostic methods used for intercomparison. Section 4 presents and analyses the results and Sect. 5 concludes the study with a summary and outlook.

\footnotetext{
${ }^{1}$ The ALADIN-HIRLAM NWP system is used for operational weather forecasting by 26 national meteorological services in Europe and North Africa which form the HIRLAM (http: //hirlam.org, last access: 14 May 2018) and ALADIN (http:// www.cnrm-game-meteo.fr/aladin/, last access: 14 May 2018) consortia. The acronym HARMONIE (HIRLAM ALADIN Regional Mesoscale Operational NWP in Europe) denotes the specific configuration of the ALADIN-HIRLAM system that is maintained by the HIRLAM consortium. The dynamical core and physical parametrizations of HARMONIE-AROME (Bengtsson et al., 2017) are based on AROME, the high-resolution limited-area model originally developed at Météo-France (Seity et al., 2011; Termonia et al., 2018).
}

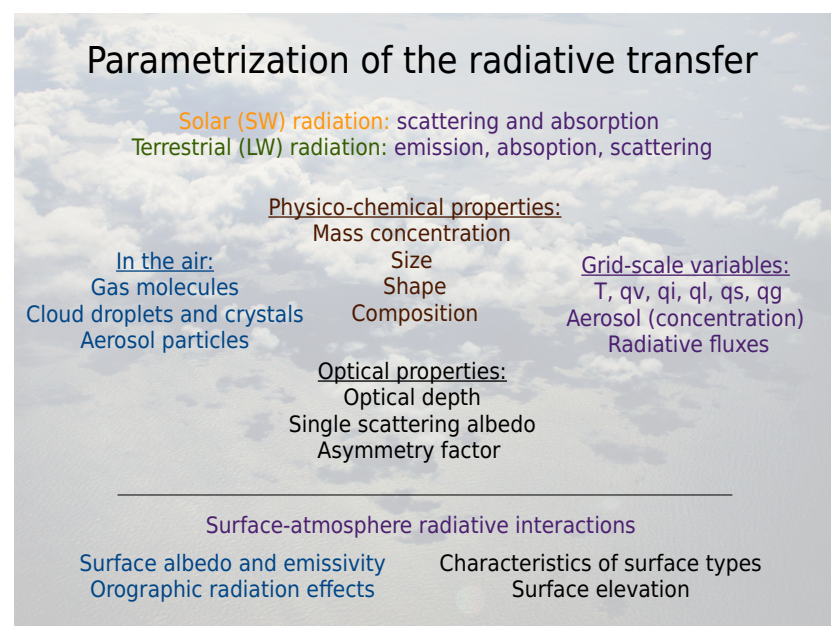

Figure 1. Parametrization of the radiative transfer. qv, qi, ql, qs and qg refer to specific content $\left(\mathrm{kg} \mathrm{kg}^{-1}\right.$ in a grid cell) of water vapour, cloud ice, liquid and precipitating snow and graupel, respectively.

\section{Radiation parametrizations of HARMONIE-AROME}

Three schemes are available for radiative transfer parametrization within a development version of HARMONIE-AROME (based on version 40h1): the default IFS radiation (ECMWF, 2015), denoted hereafter as IFSRADIA, and the single spectral interval schemes ACRANEB v.2 (Mašek et al., 2016; Geleyn et al., 2017, hereafter denoted as ACRANEB) and HLRADIA (Rontu et al., 2017), which can be run at high temporal and spatial resolutions at the expense of high spectral resolution.

The tasks, input and output of every radiation scheme within HARMONIE-AROME are schematically depicted in Fig. 1. Radiation schemes estimate the radiative heating in the atmosphere due to the vertical divergence of the net longwave (LW, terrestrial) and net SW (solar) radiation fluxes. The radiative heating is a source term in the thermodynamics equation in the model and influences the development of atmospheric temperatures and the evolution of clouds. At the surface level, radiation parametrizations provide the model with the downward (LWDS, SWDS) and upward (LWUS, SWUS) LW and SW radiation fluxes. These are part of the surface energy balance and a lower boundary condition for the calculation of atmospheric radiation transfer. Atmospheric gas composition, aerosol and cloud liquid and ice particle mass distribution and optical properties are used as input for the radiative transfer calculations at each time step in every grid cell of the 3-D model. The radiative properties of the surface (i.e. surface temperature, albedo and emissivity) are also required as input to the radiation schemes. 


\subsection{IFSRADIA}

By default, a version of IFSRADIA applied before 2007 and based on cycle 25R (ECMWF, 2015, Sect. 2.2) is applied for the radiative transfer calculations in the HARMONIEAROME forecast model. It has 6 spectral intervals in SW range between 0.2 and $12.195 \mu \mathrm{m}$ and 16 in LW from 3.08 to $1000 \mu \mathrm{m}$. Cloud optical properties are based on grid-scale temperature, cloud cover, liquid water and ice crystal content and parametrized cloud particle effective radius. Climatological fields of ozone and aerosol are used together with the predicted water vapour content and prescribed values of the rest of atmospheric gas concentrations. By default, this scheme is called every 15 th minute during the model integration.

\subsection{ACRANEB}

ACRANEB radiation parametrization has been used in the ALADIN NWP model (Termonia et al., 2018) since the 1990s. Its renewed version was introduced also to HARMONIE-AROME in 2014. This is a broadband scheme with one spectral band for SW and another for LW. The optical properties of atmospheric gases, cloud and aerosol particles and the surface are derived from the same input as for IFSRADIA. ACRANEB includes advanced treatment of LW interactions between the atmospheric layers resolved by the NWP model, The intermittency in time can be configured as requested by the NWP model setup. By default, the cloud-radiation interactions are fully accounted for at each time step while the impact of atmospheric gaseous components is calculated less frequently.

\subsection{HLRADIA}

This scheme originally comes from the HIRLAM NWP model (Undén et al., 2002). A pioneering study by Savijärvi (1990) suggested a fast radiation scheme for mesoscale NWP models in which the radiative transfer was heavily parametrized in order to make the scheme very fast for shortrange, limited-area NWP use. This was achieved using one vertical loop for both the LW and SW spectral intervals. This results in simplified treatment of radiation interactions between atmospheric (cloud) layers. HLRADIA has been used for operational weather prediction since 1994 (Eerola, 2013). The scheme was implemented (Nielsen et al., 2014) into HARMONIE-AROME and its latest version is documented by Rontu et al. (2017). HLRADIA is always called every time step. Input data of the atmospheric gaseous components, cloud liquid and ice concentrations are the same as for IFRADIA and ACRANEB while aerosol and ozone impacts are approximated with constant coefficients for both the SW and LW intervals.

\section{Model-observation comparisons in spring 2017}

The period March-April-May (MAM) 2017 over Finland was chosen for the model-observation intercomparison. Especially in May, the weather in Scandinavia was dominated by a cold Arctic airflow. Convective clouds formed over the land areas heated by the Sun and light snowfall was frequent until the end of May in Finland. Over the cold sea and lake areas, clear skies were prevalent. The composite Fig. 2 illustrates the cloud distribution during the 10-day period from 7 to 16 May, as seen in the images of the VIIRS instrument onboard Suomi NPP polar-orbiting satellite (https:// lance.modaps.eosdis.nasa.gov/cgi-bin/imagery/viirs.cgi, last access: 14 May 2018).

In these conditions, comparing the coastal and inland global radiation observations to the model output was expected to reveal interesting local differences while the averaged verification statistics of the screen-level variables were expected to show only minor differences.

\subsection{Observations}

A map of the global radiation measurement stations used in this study is shown in Fig. 3. These stations belong to the solar radiation measurement network of the Finnish Meteorological Institute (FMI), where global radiation is measured using ventilated Kipp and Zonen CM11 secondary standard pyranometers. The instruments are calibrated yearly or every second year. The data have been tested using the quality assurance procedures defined for the Baseline Surface Radiation Network (Long and Shi, 2008), with minor modifications to better suit Finnish conditions. In this study, hourly values of the global radiation were used. Based on a more detailed analysis of the Swedish radiation measurement network (Persson, 2000), the uncertainty of these hourly values is estimated to be roughly $4 \%$, except for low Sun elevations when larger uncertainty is expected.

\subsection{Experiment setup}

HARMONIE experiments run for MAM 2017 are summarized in Table 1. In addition to the use of the different radiation schemes, only minor changes with the respect to the default settings (Bengtsson et al., 2017) were applied. Cloud liquid droplet and ice crystal mass, along with $80 \%$ of the precipitating graupel mass (specific content in $\mathrm{kg} / \mathrm{kg}$ per grid cell at each time step) were given as input to all three radiation schemes. Inclusion of the precipitating solid particles (graupel, snow) but assuming the same optical properties for them as for pristine ice crystals has only been motivated empirically (Bengtsson et al., 2017) and is expected to influence differently each of the three radiation schemes. Here, addition of only $80 \%$ of graupel and no snow was chosen as a compromise for testing. Aerosol optical depth (AOD at $550 \mathrm{~nm}$ ), based on 2003-2011 CAMS climatology 


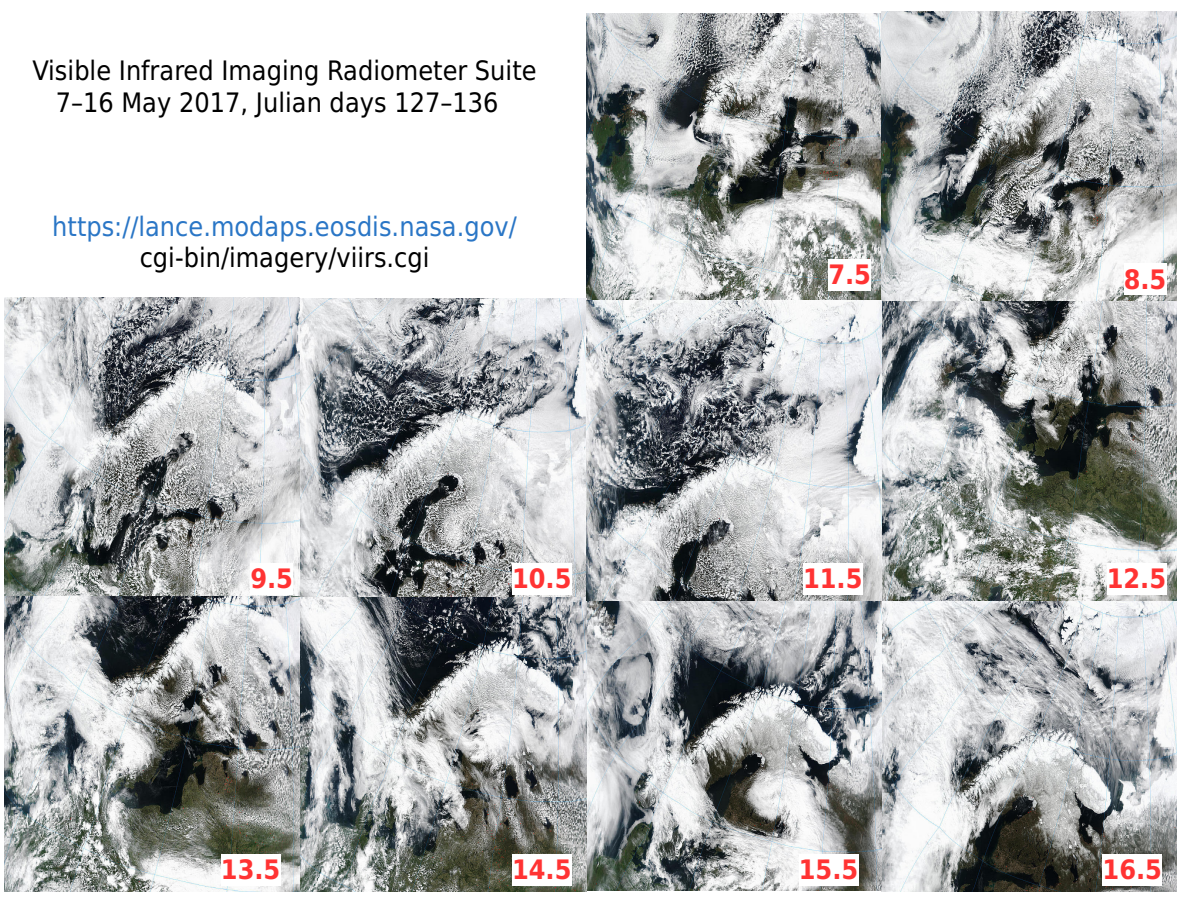

Figure 2. VIIRS images from 7 to 16 May, satellite overpasses around midday local time in this area. An example of forecasts valid at the 10 May will be discussed in Sect. 4.2.

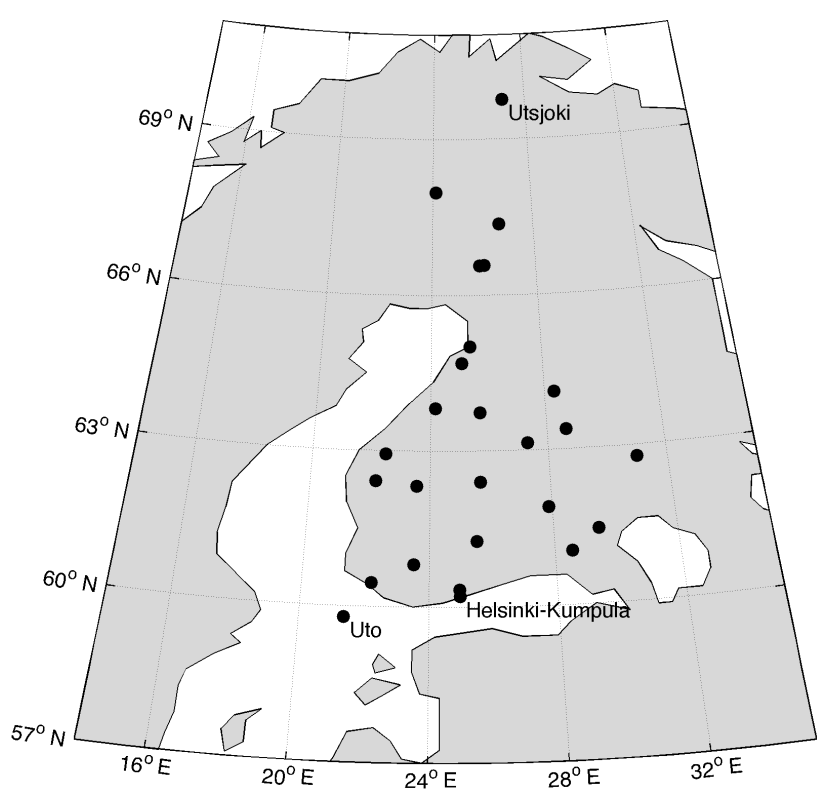

Figure 3. Location of global radiation measurement stations in Finland. The marked stations Helsinki-Kumpula $\left(60.203^{\circ} \mathrm{N}\right.$, $\left.24.961^{\circ} \mathrm{E}\right)$, Utö $\left(59.779^{\circ} \mathrm{N}, 21.375^{\circ} \mathrm{E}\right)$ and Utsjoki $\left(69.756^{\circ} \mathrm{N}\right.$, $\left.27.007^{\circ} \mathrm{E}\right)$ are referred to in Sect. 4.2.
(Bozzo et al., 2017), was used as input for IFSRADIA and ACRANEB instead of the default Tegen AOD (Tegen et al., 1997), while the HLRADIA used constant coefficients to account for aerosol absorption and scattering (Rontu et al., 2017).

\subsection{Diagnostics}

Model-observation intercomparisons included standard verification against the screen-level temperature $\left(T_{2} \mathrm{~m}\right)$ and total cloud cover for each month of MAM 2017. Comparison of the predicted daily and hourly global radiation fluxes (SWDS) at selected measurement stations in Finland was done for the same 3-month period. In addition, the experiment results were compared to each other. For this, the monthly mean accumulated SWDS and LWDS as well as the average instantaneous cloud condensate content and $T_{2 \mathrm{~m}}$ were considered, all based on $+24 \mathrm{~h}$ forecasts starting at midnight or midday. Results representing a typical day of evolving convection, 10 May 2017, are demonstrated separately.

\section{Results}

\subsection{Forecast radiation fluxes and weather parameters}

The standard station verification of $T_{2} \mathrm{~m}$ and the total cloud cover showed a small bias, standard deviation error and mi- 
Table 1. HARMONIE experiments for MAM 2017.

\begin{tabular}{ll}
\hline Domain & Finland \\
Model horizontal/vertical resolution & $2.5 \mathrm{~km} / 65$ levels \\
HARMONIE version & $40 \mathrm{~h} 1$. radiation \\
Radiation schemes & IFSRADIA, ACRANEB, HLRADIA \\
Data assimilation & Default atmospheric (3DVAR) and surface analysis \\
Lateral boundaries & ECMWF forecast \\
Forecast & up to $+27 \mathrm{~h}$ initiated every $3 \mathrm{~h}$ for 1 March-31 May \\
\hline
\end{tabular}
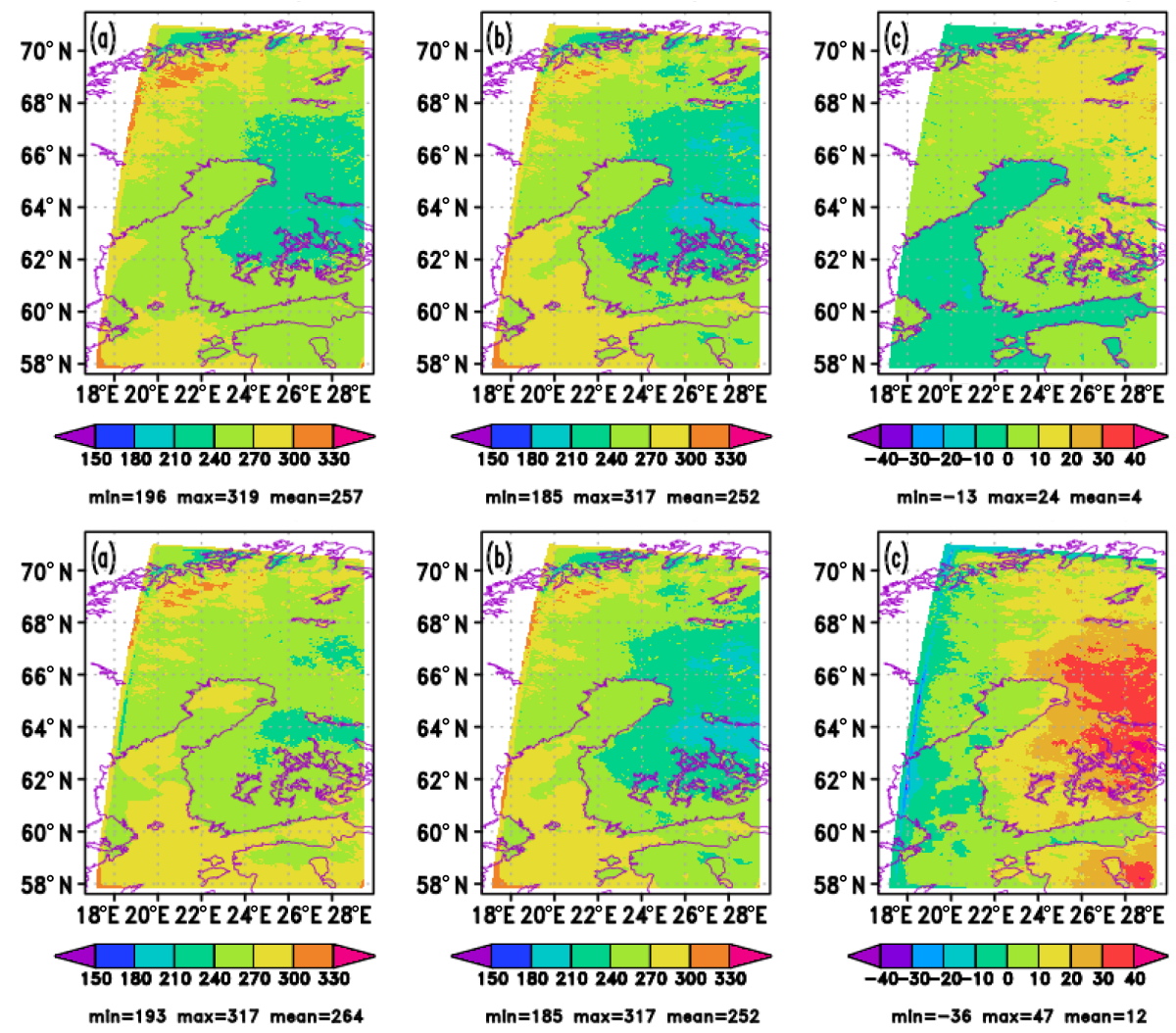

Figure 4. Monthly mean SWDS for May 2017, based on accumulated flux by the $+24 \mathrm{~h}$ forecasts started every 00:00 UTC (W $\mathrm{m}^{-2}$ ). Upper row panels: (a) ACRANEB, (b) IFSRADIA and (c) their difference. Lower row panels: (a) HLRADIA, (b) IFSRADIA and (c) their difference. Minimum, maximum and mean values are shown under the colour scales for each subfigure. Note that for clarity the same IFSRADIA figure is shown in the middle of both panels.

nor differences between the experiments over the study area during the 3-month periods (not shown). As expected, these indicators tend to smooth out local and temporal features and are thus less suitable for detailed studies related to the impact of different physical parametrizations. However, we can conclude that the use of the different radiation schemes did not lead to significant changes in model quality as measured with $T_{2 \mathrm{~m}}$ and cloudiness.

Monthly mean SWDS for May 2017 resulting from the application of IFSRADIA, ACRANEB and HLRADIA and the difference of ACRANEB and HLRADIA from IFSRADIA is shown in Fig. 4; the LWDS is shown in Fig. 5. Compared to HARMONIE-AROME, which used IFSRADIA, the broad- band schemes ACRANEB and HLRADIA tended to overestimate SWDS by 4 and $12 \mathrm{~W} \mathrm{~m}^{-2}$, respectively. Usage of ACRANEB results in LWDS which was on average $2 \mathrm{~W} \mathrm{~m}^{-2}$ larger than that by IFSRADIA, while HLRADIA usage results in $9 \mathrm{~W} \mathrm{~m}^{-2}$ smaller LWDS compared to IFSRADIA. The cloud liquid water path of the ACRANEB experiment was $0.016 \mathrm{~g} \mathrm{~m}^{-2}$ smaller than that of the IFSRADIA experiment, while HLRADIA experiment showed a larger deviation, $0.064 \mathrm{~g} \mathrm{~m}^{-2}$ smaller mean value than IFSRADIA.

The larger SWDS and smaller LWDS due to HLRADIA usage were related to more transparent clouds. For ACRANEB, the main difference from IFSRADIA in SWDS seems to come from the Baltic Sea area while for HLRADIA 

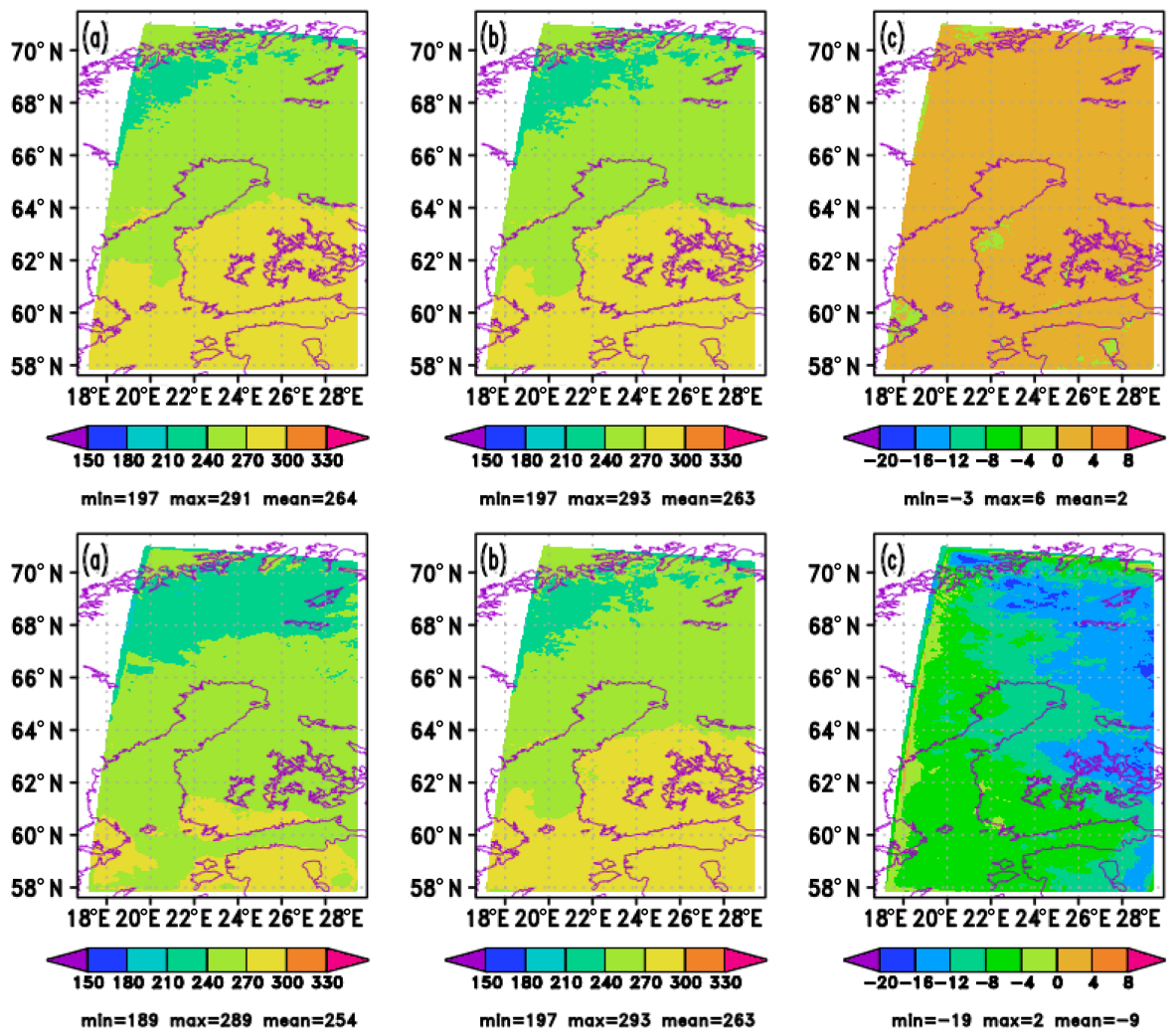

Figure 5. As in Fig. 4 but for LWDS.

the (less cloudy than the IFSRADIA experiment) land areas seem to be the main source of the SWDS difference. For LWDS, HLRADIA values were systematically smaller than those due to IFSRADIA, also with the maximum difference over the eastern land area. At the monthly level, the mean differences and areal variations of both SW and LW downwelling radiation fluxes were thus related to the cloud properties and their variations. Next, we will compare the details of the predicted SWDS to the observations over land and sea areas.

\subsection{Global radiation at the measurement stations}

Time series of the forecast SWDS vs. the observed global radiation daily averages for the whole MAM period are shown in Fig. 6 for the southernmost measurement station Utö, representing open sea conditions, and for the northernmost station Utsjoki, representing Arctic land area environment. The forecast values by the different experiments follow each other more closely than they follow the observed values. Usage of HLRADIA seems to lead to the largest SWDS and IFSRADIA to the smallest. The observed daily averages tend to be lower than the forecast ones, especially when the fluxes are smaller due to clouds and lower solar elevation. Most probably the differences between the observed and forecast SWDS are due to the differences in observed and simulated clouds as already indicated by the comparisons in Sect. 4.1. However, when the solar elevation is small and cloudy conditions prevail, also the observation uncertainty may influence the comparison (Sect. 3.1). The Utö and Utsjoki examples were representative among all stations for this period (not shown).

Hourly SWDS forecasts, based on the +3 to $+6 \mathrm{~h}$ forecasts initiated every $3 \mathrm{~h}$, are compared to hourly observations for the period from 8 to 16 May in Fig. 7. During this week, evolution of convection and its inhibition over cold sea and lake areas were evident (see the satellite images in Fig. 2). This is seen especially clearly on 10 May. Utö and HelsinkiKumpula measurements were selected for comparison. The influence of convective clouds on SWDS is seen 8-11 and 15 May in Kumpula, while in Utö clear skies prevailed all days but 15 May (Fig. 7). The difference between the radiation parametrizations showed up during the cloudy-sky cases while the predicted global radiation flux was very close to observed during the clear-sky cases. In these cases, the maximum values were slightly underestimated by all experiments compared to observations.

The difference between HARMONIE forecasts using ACRANEB and HLRADIA from those using IFSRADIA is further demonstrated by the maps for 10 May (Figs. 8 and 9), which depict the differences of predicted SWDS, LWDS, $T_{2 \mathrm{~m}}$ and total cloud cover for ACRANEB-IFSRADIA 

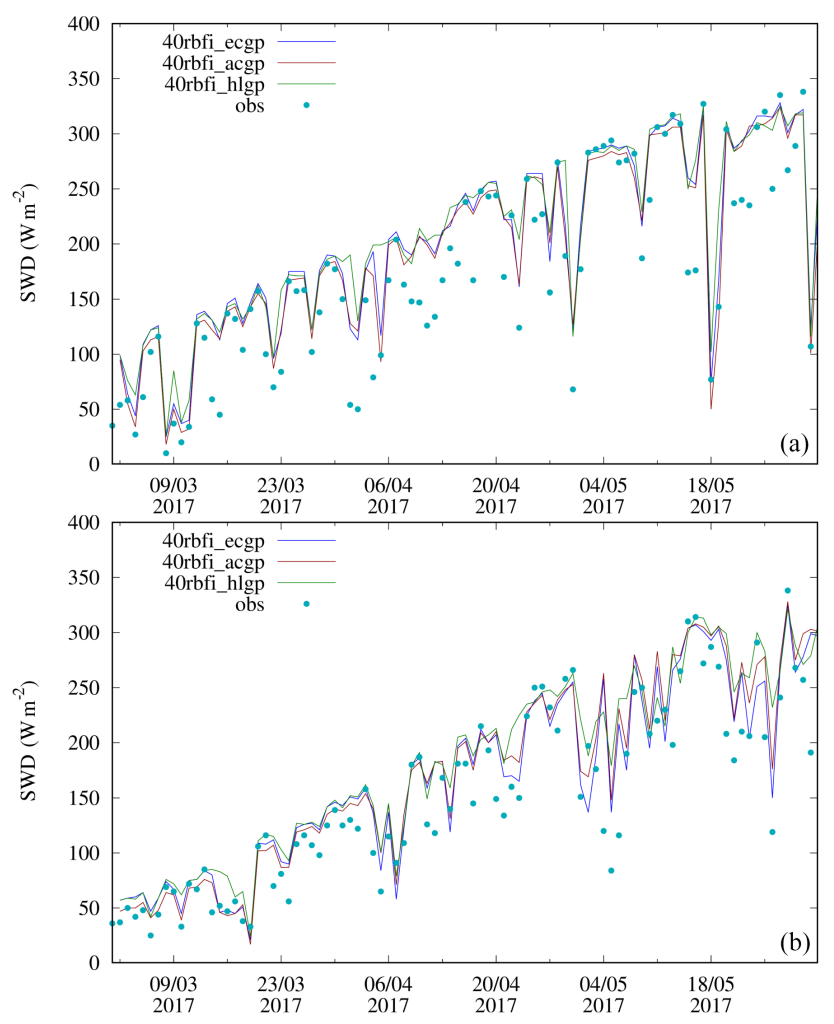

Figure 6. HARMONIE forecast $\operatorname{SWDS}\left(\mathrm{W} \mathrm{m}^{-2}\right)$ vs. observed global radiation daily averaged from 00:00 UTC $+24 \mathrm{~h}$ for MAM 2017: Utö (a) and Utsjoki (b). Observations are shown with cyan dots, the forecasts with lines: IFSRADIA is blue, ACRANEB is red and HLRADIA is green.

and HLRADIA-IFSRADIA forecasts valid at 12:00 UTC $(2017050912+24 \mathrm{~h})$. Note that the radiation fluxes are accumulated during the forecast while $T_{2 \mathrm{~m}}$ and total cloud cover represent instantaneous values at 12:00 UTC. The local differences are most clearly seen for the screen-level temperature and the cloud cover which both show a spotty structure. In addition, the daily average SWDS shows a systematic larger-scale overestimation by ACRANEB $\left(+8 \mathrm{~W} \mathrm{~m}^{-2}\right.$ averaged over the experiment domain) and HLRADIA $\left(+12 \mathrm{~W} \mathrm{~m}^{-2}\right)$. An underestimation of LWDS $\left(-13 \mathrm{~W} \mathrm{~m}^{-2}\right)$ by HLRADIA as compared to IFSRADIA is seen, while the ACRANEB result $\left(+3 \mathrm{~W} \mathrm{~m}^{-2}\right)$ was close to IFSRADIA. Correspondingly, the area-averaged $T_{2 \mathrm{~m}}$ and total cloud cover were slightly overestimated for both ACRANEB and HLRADIA as compared to IFSRADIA.

For this $+24 \mathrm{~h}$ period, the average observed SWDS over all Finnish measurement stations was ca. $200 \mathrm{~W} \mathrm{~m}^{-2}$, while the average SWDS forecast over the land areas of Finland varied from $231 \mathrm{~W} \mathrm{~m}^{-2}$ (IFSRADIA) to $236 \mathrm{~W} \mathrm{~m}^{-2}$ (ACRANEB) and $243 \mathrm{~W} \mathrm{~m}^{-2}$ (HLRADIA). This indicates similar overestimation of SWDS by the model that was seen in Fig. 6 for the selected stations. However, the averages of measured and simulated fluxes are not directly comparable due to the dif-
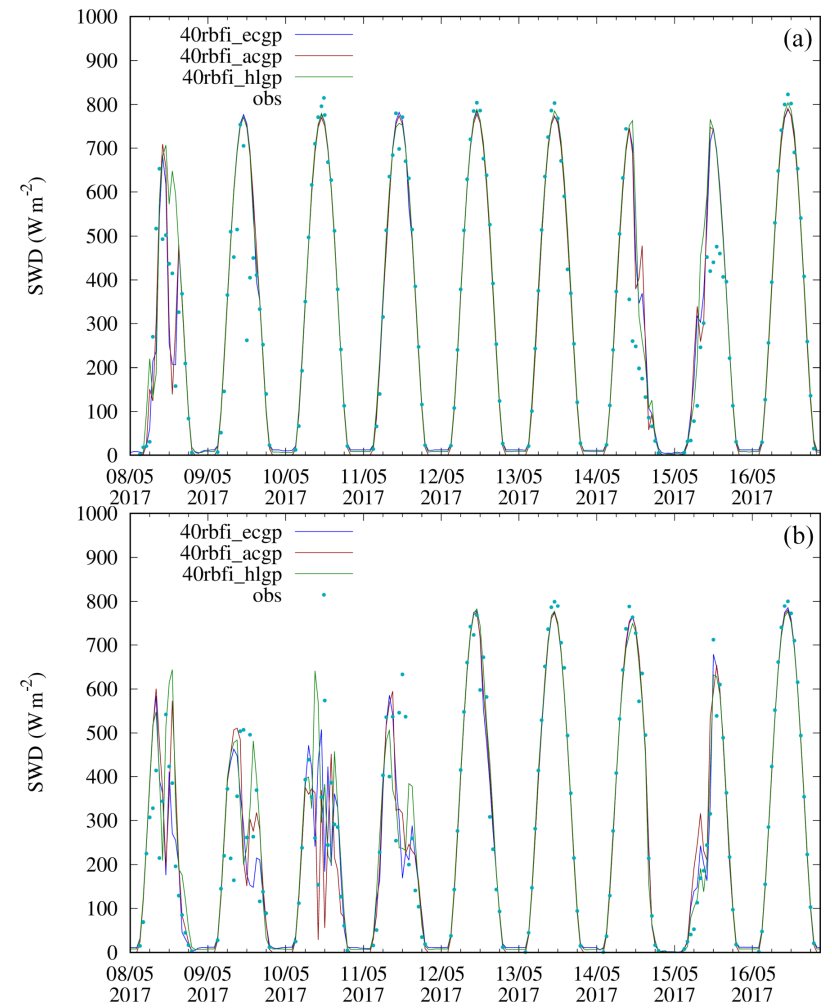

Figure 7. HARMONIE forecast SWDS $\left(\mathrm{W} \mathrm{m}^{-2}\right)$ hourly averaged from 00:00 UTC+04-03, +05-+04 and +06-+05 h vs. observed hourly global radiation for 8-16 May 2017: Utö (a) and HelsinkiKumpula (b). Observations are shown with cyan dots, the forecasts with lines: IFSRADIA is blue, ACRANEB is red and HLRADIA is green.

ferent domains represented by the observations and by the model.

\section{Conclusions and outlook}

Global radiation (SWDS) fluxes due to three radiation schemes - IFSRADIA, ACRANEB and HLRADIA showed similar results and the time series at observation stations agreed generally well with the measurements. Typically, $+24 \mathrm{~h}$ averaged model results were overestimated as compared to the daily mean observations, presumably due to the inaccuracies in the cloud simulation. The relative difference was the largest when the flux was small.

According to the hourly observations, slight underestimation of SWDS, based on the +3-+6h HARMONIE forecasts, occurred only in very clear, clean cases. Generally, the agreement between the model and observations was better than in the comparison of daily averages. The reason is again most probably related to the cloud uncertainties, which would influence the shorter forecasts less than the longer ones. 


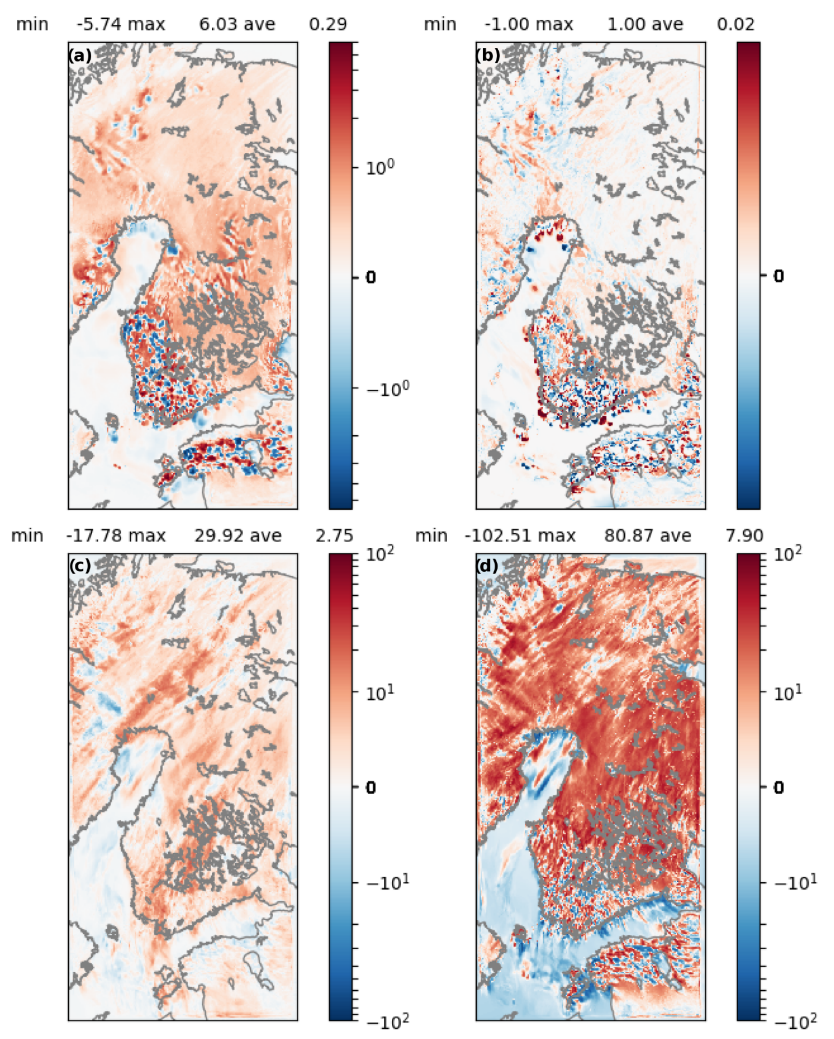

Figure 8. Difference of HARMONIE forecasts $2017050912+24 \mathrm{~h}$ valid at 2017051012 using ACRANEB vs. IFSRADIA: (a) $T_{2} \mathrm{~m}$ $\left({ }^{\circ} \mathrm{C}\right)$, (b) total cloud cover $[0,1]$, (c) average LWDS $\left(\mathrm{W} \mathrm{m}^{-2}\right)$ and (d) $24 \mathrm{~h}$ average $\operatorname{SWDS}\left(\mathrm{W} \mathrm{m}^{-2}\right)$.

In cloudy-sky cases, there were large temporal and spatial variations of SWDS and LWDS between the schemes. Differences between observed and simulated SWDS could be locally large. Averaged over the domain, $T_{2 \mathrm{~m}}$ and cloud fraction showed only small differences, which are not easy to detect or interpret based on the standard station verification.

The cloud liquid water mass, resulting from the application of HLRADIA, seems underestimated when compared to IFSRADIA and ACRANEB. This suggests stronger cloudradiation interactions in HARMONIE when using HLRADIA. Correspondingly, SWDS became overestimated and LWDS underestimated by HLRADIA compared to IFSRADIA/ACRANEB. Further comparisons, which would use also cloud liquid and ice content observations, are needed to understand the interactions better.

We found a systematic difference of LW downwelling radiation fluxes between HLRADIA on one hand and IFSRADIA and ACRANEB on the other hand. A further study using LWDS measurements is needed to confirm whether this difference indicates a need for serious improvements in the HLRADIA LW parametrizations (as suggested by Rontu et al., 2017).

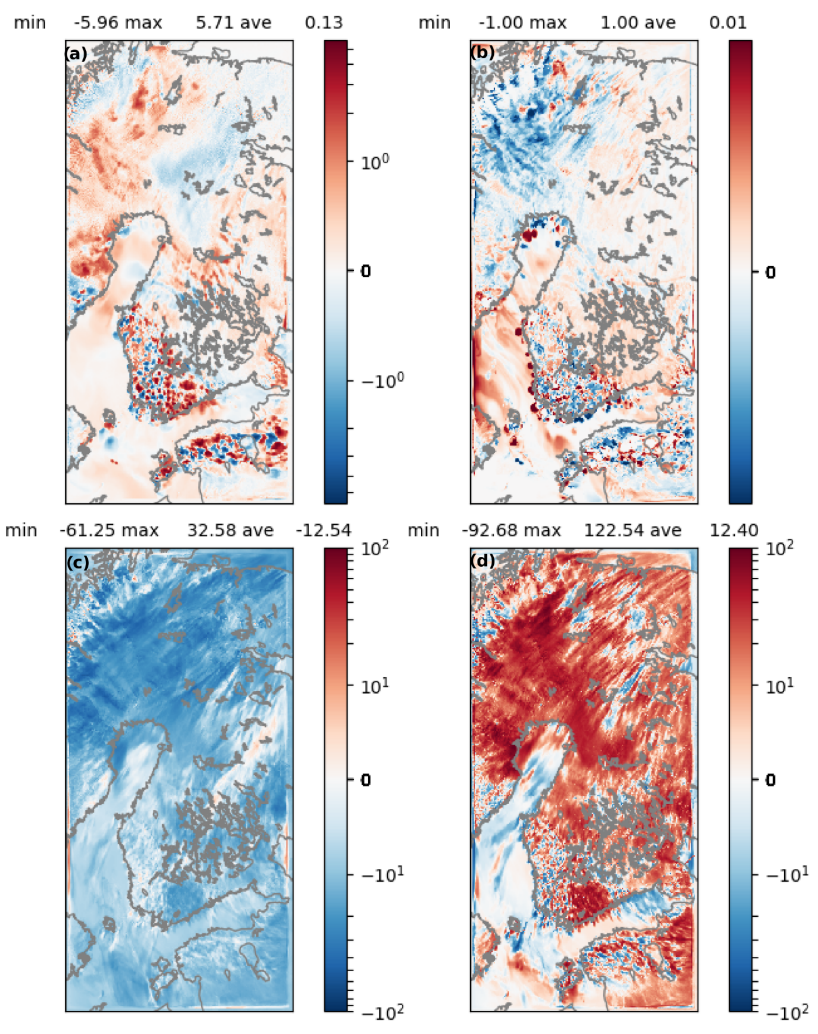

Figure 9. As in Fig. 8 but for HLRADIA vs. IFSRADIA.

To summarize the results in terms of the questions stated in the introduction: we found systematic difference between the observed and predicted daily global radiation by all three schemes. In this respect all schemes showed up equally reliable. We saw local and temporal variations between the schemes and observations, related to cloudiness and cloudradiation interactions. Dedicated experiments should be set up to study whether these variations would give sufficient spread for an ensemble system, influencing the important output variables like solar energy potential or the nearsurface weather characteristics.

In this study we used regular global radiation observations from the FMI solar radiation measurement network. A simple comparison of time series turned out to be useful for the model-observation comparisons. Inclusion of SWDS observations in the operational NWP verification system would allow systematic comparisons and application of more advanced verification scores on a regular basis.

Data availability. Underlying research data consist of hourly global radiation measurements picked from the FMI climate data base and HARMONIE-AROME forecasts for the period MAM 2017. Attached to this article are files containing point values picked from the $+3-+6 \mathrm{~h}$ forecasts of the three experiments and the corresponding SWDS measurements. Selected HARMONIE-AROME forecast grib files from the three experiments (ca. $20 \mathrm{~GB}$ of data ex- 
tracted from the experiment output) are available from the authors upon request.

\section{The Supplement related to this article is available online at https://doi.org/10.5194/asr-15-81-2018-supplement.}

Competing interests. The authors declare that they have no conflict of interest.

Special issue statement. This article is part of the special issue "17th EMS Annual Meeting: European Conference for Applied Meteorology and Climatology 2017'. It is a result of the EMS Annual Meeting: European Conference for Applied Meteorology and Climatology 2017, Dublin, Ireland, 4-8 September 2017.

Acknowledgements. The support of the International HIRLAM$\mathrm{C}$ and ALADIN programmes is acknowledged. We thank the Strategic Research Council at the Academy of Finland for funding through the BCDC Energy project (decision 292854 and 314167).

Edited by: Emily Gleeson

Reviewed by: two anonymous referees

\section{References}

Ahlgrimm, M. and Forbes, R.: The Impact of Low Clouds on Surface Shortwave Radiation in the ECMWF Model, Mon, Weather Rev,, 140, 3783-3794, https://doi.org/10.1175/MWRD-11-00316.1, 2012.

Antonanzas, J., Osorio, N., Escobar, R., Urraca, R., de Pison, F. M., and Antonanzas-Torres, F.: Review of photovoltaic power forecasting, Solar Energy, 136, 78-111, https://doi.org/10.1016/j.solener.2016.06.069, 2016.

Bengtsson, L., Andrae, U.,Aspelien, T., Batrak, Y., Calvo, J., de Rooy, W., Gleeson, E., Hansen-Sass, B., Homleid, M., Hortal, M., Ivarsson, K., Lenderink, G., Niemelä, S., Pagh Nielsen, K., Onvlee, J., Rontu, L., Samuelsson, P., Santos Muñoz, D., Subias, A., Tijm, S., Toll, V., Yang, X., and Ødegaard Køltzow, M.: The HARMONIE-AROME model configuration in the ALADIN-HIRLAM NWP system, Monthly Weather Rev., 145, 1919-1935, https://doi.org/10.1175/MWR-D-16-0417.1

Bozzo, A., Remy, S., Benedetti, A., Flemming, J., Bechtold, P., Rodwell, M. J., and Morcrette, J.-J., 2017. Implementation of a CAMS-based aerosol climatology in the IFS, Technical Memorandum 801, available at http://www.ecmwf.int/en/elibrary/ 17219-implementation-cams-based-aerosol-climatology-ifs (last access: 14 May 2018), 2017.

ECMWF: IFS documentation, chap. 2, available at: http://www.ecmwf.int/sites/default/files/elibrary/2015/ 9211-part-iv-physical-processes.pdf (last access: 14 May 2018), 2015
Eerola, K.: Twenty-one years of verification from the HIRLAM NWP system, Weather Forecast., 28, 270-285, https://doi.org/10.1175/WAF-D-12-00068.1, 2013.

Federico, S., Torcasio, R. C., Sanò, P., Casella, D., Campanelli, M., Meirink, J. F., Wang, P., Vergari, S., Diémoz, H., and Dietrich, S.: Comparison of hourly surface downwelling solar radiation estimated from MSG-SEVIRI and forecast by the RAMS model with pyranometers over Italy, Atmos. Meas. Tech., 10, 2337 2352, https://doi.org/10.5194/amt-10-2337-2017, 2017.

Geleyn, J. F., Mašek, J., Brožková, R., Kuma, P., Degrauwe, D., Hello, G., and Pristov, N.: Single interval longwave radiation scheme based on the net exchanged rate decomposition with bracketing, Q. J. Roy. Meteorol. Soc., 143, 1313-1335, https://doi.org/10.1002/qj.3006, 2017.

Kangas, M., Rontu, L., Fortelius, C., Aurela, M., and Poikonen, A.: Weather model verification using Sodankylä mast measurements, Geosci. Instrum. Method. Data Syst., 5, 75-84, https://doi.org/10.5194/gi-5-75-2016, 2016.

Köhler, C., Steiner, A., Saint-Drenan, Y.-M., Ernst, D., BergmannDick, A., Zirkelbach, M., Bouallègue, Z. B., Metzinger, I., and Ritter, B.: Critical weather situations for renewable energies part b: Low stratus risk for solar power, Renewable Energy, 101, 794-803, https://doi.org/10.1016/j.renene.2016.09.002, 2017.

Kosmopoulos, P., Kazadzis, S., Lagouvardos, K., Kotroni, V., and Bais, A.: Solar energy prediction and verification using operational model forecasts and groundbased solar measurements, Energy, 93, 1918-1930, https://doi.org/10.1016/j.energy.2015.10.054, 2015.

Lara-Fanego, V., Ruiz-Arias, J., Pozo-Vázquez, D., SantosAlamillos, F., and Tovar-Pescador, J.: Evaluation of the WRF model solar irradiance forecasts in Andalusia (southern Spain), Solar Energy, 86, 2200-2217, https://doi.org/10.1016/j.solener.2011.02.014, 2012.

Long, C. and Shi, Y.: An Automated Quality Assessment and Control Algorithm for Surface Radiation Measurements, Open Atmos. Sci. J., 12, 23-37, https://doi.org/10.2174/1874282300802010023, 2008.

Mašek, J., Geleyn, J. F., Brožková, R., Giot, O., Achom, H. O., and Kuma, P.: Single interval shortwave radiation scheme with parameterized optical saturation and spectral overlaps, Q. J. Roy. Meteorol. Soc., 142, 304-326, https://doi.org/10.1002/qj.2653, 2016.

Nielsen, K. P., Gleeson, E., and Rontu, L.: Radiation sensitivity tests of the HARMONIE 37h1 NWP model, Geosci. Model Dev., 7, 1433-1449, https://doi.org/10.5194/gmd-7-1433-2014, 2014.

Nielsen, K. P., Georgoulias, A. K., Kourtidis, K., and Stathopoulos, S.: Relationship between air pollution and meteorology, Deliverable D 5.4 from the EU FP7 project: Monitoring and Assessment of Regional air quality in China using space Observations (MarcoPolo), available at: https://www.researchgate.net/profile/ Kristian_Nielsen/project (last access: 14 May 2018), 2017.

Persson, T.: Measurements of solar radiation in Sweden 1983-1998, SMHI Reports Meteorology and Climatology, vol. RMK No. 89, Swedish Meteorological and Hydrological Institute, Norrköping, Sweden, 2000.

Rontu, L., Wastl, C., and Niemelä, S.: Influence of the details of topography on weather forecast - evaluation of HARMONIE experiments in the Sochi Olympics domain 
over the Caucasian mountains, Front. Earth Sci., 4, 13 pp., https://doi.org/10.3389/feart.2016.00013, 2016.

Rontu, L., Gleeson, E., Räisänen, P., Nielsen, K. P., Savijärvi, H., and Sass, B. H.: The HIRLAM fast radiation scheme for mesoscale numerical weather prediction models, Adv. Sci. Res., 14, 195-215, https://doi.org/10.5194/asr-14-195-2017, 2017.

Savijärvi, H.: Fast Radiation Parameterization Schemes for Mesoscale and Short-Range Forecast Models, 1990, J. Appl. Meteorol., 29, 437-447, https://doi.org/10.1175/15200450(1990)029<0437:FRPSFM>2.0.CO;2, 1990.

Seity, Y., Brousseu, P., Malardel, S., Hello, G., Benard, P., Bouttier, F., Lac, C., and Masson, V.: The AROME-France convectivescale operational model, Mon. Weather Rev., 139, 976-991, https://doi.org/10.1175/2010MWR3425.1, 2011.

Tegen, I., Hoorig, P., Chin, M., Fung, I., Jacob, D., and Penner, J.: Contribution of different aerosol species to the global aerosol extinction optical thickness: Estimates from model results, J. Geophys. Res., 102, 23895-23915, https://doi.org/10.1029/97JD01864, 1997.
Termonia, P., Fischer, C., Bazile, E., Bouyssel, F., Brožková, R., Bénard, P., Bochenek, B., Degrauwe, D., Derková, M., El Khatib, R., Hamdi, R., Mašek, J., Pottier, P., Pristov, N., Seity, Y., Smolíková, P., Španiel, O., Tudor, M., Wang, Y., Wittmann, C., and Joly, A.: The ALADIN System and its canonical model configurations AROME CY41T1 and ALARO CY40T1, Geosci. Model Dev., 11, 257-281, https://doi.org/10.5194/gmd-11-2572018, 2018.

Undén, P., Rontu, L., Arvinen, H., Lynch, P., Calvo, J., Cats, G., Cuxart, J., Eerola, K., Fortelius, C., Garcia-Moya, J. A., Jones, C., Lenderlink, G., McDonald, A., McGrath, R., Navascues, B., Woetman Nielsen, N., Odegaard, V., Rodriguez, E., Rummukainen, M., Room, R., Sattler, K., Hansen Sass, B., Savijärvi, H., Wichers Schreur, B., Sigg, R., The, H., and Tijm, A.: The HIRLAM version 5.0 model, HIRLAM documentation manual (HIRLAM Scientific Documentation), available at: http://www.hirlam.org (last access: 14 April 2018), 2002. 